\title{
UJI PENGGUNAAN BERBAGAI MEDIA TUMBUH DAN PEMBERIAN PUPUK GROWMORE PADA AKLIMATISASI TANAMAN ANGGREK Dendrobium
}

\author{
GUSTI MARLINA ${ }^{1}$, MARLINDA ${ }^{2}$, dan HENI ROSNETI ${ }^{3}$ \\ ${ }^{1 * 23}$ Universitas Islam Kuantan Singingi \\ Universitas Islam Kuantan Singingi, Teluk Kuantan 2017 \\ Jl. Gatot Subroto KM 7 Jake Tlp. 081268855945 \\ "E-mail : marlina.gusti979@gmail.com
}

\begin{abstract}
ABSTRAK
Tujuan penelitian yaitu mengetahui pengaruh berbagai media tumbuh dan pemberian pupuk growmore pada aklimatisasi tanaman anggrek Dendrobium. Penelitian ini menggunakan Rancangan Acak Lengkap (RAL) Faktorial yang terdiri dari 2 faktor, faktor pertama adalah faktor (M) media tumbuh yang terdiri dari 3 taraf yaitu: M1 (media akar pakis), M2 (media arang kayu), M3 (media sabut kelapa) dan faktor kedua adalah $(\mathrm{G})$ pemberian pupuk growmore yang terdiri dari 4 taraf yaitu : G0 (tanpa pemberian pupuk Growmore), G1 (pemberian pupuk Growmore 2 gr/liter), G2 (pemberian pupuk Growmore 4 gr/liter), G3 (pemberian pupuk Growmore $6 \mathrm{gr} /$ liter). Untuk mengetahui pertumbuhan tanaman anggrek maka dilakukan pengamatan dengan parameter sebagai berikut : Persentase Tumbuh (\%), Tinggi Tanaman (cm), Jumlah daun (helai), dan Jumlah anakan (batang). Kemudian data-data yang diperoleh dianalisis secara statistik, maka dilanjutkan dengan uji Lanjut Beda Nyata Jujur (BNJ) pada taraf 5\%. Hasil penelitian menunjukan bahwa perlakuan secara tunggal penggunaan media tumbuh tidak memberikan pengaruh yang nyata terhadap parameter pengamatan persentase tumbuh (\%), tinggi tanaman $(\mathrm{cm})$, jumlah daun (helai), dan jumlah anakan (batang). Untuk pemberian pupuk growmore juga tidak menunjukan pengaruh yang nyata terhadap parameter pengamatan persentase tumbuh $(\%)$, tinggi tanaman $(\mathrm{cm})$, jumlah daun (helai), dan jumlah anakan (batang). Demikian juga secara interaksi penggunaan perbagai media tumbuh dan pemberian pupuk growmore tidak menunjukan pengaruh yang nyata terhadap persentase tumbuh (\%), tinggi tanaman $(\mathrm{cm})$, jumlah daun (helai), dan jumlah anakan (batang).
\end{abstract}

Kata kunci : Anggrek, akar pakis, arang kayu, sabut kelapa, pupuk growmore.

\begin{abstract}
The research objective was determine the effect of various growth media and growmore fertilizer on the acclimatization of Dendrobium orchids. study used a Completely Randomized Design (CRD) Factorial consisting of 2 factors, the first is (M) of growing media which consists of 3 levels, namely: M1 (medium fern root), M2 (wood charcoal medium), M3 (coir media coconut) and the second is $(G)$ growmore fertilizer which consists of 4 levels, namely: G0 (without Growmore fertilizer), G1 (Growmore fertilizer $2 \mathrm{~g} /$ liter), G2 (fertilizer Growmore $4 \mathrm{~g}$ / liter), G3 (Growmore fertilizer $6 \mathrm{~g} /$ liter). Determine the growth of orchid plants, observations were made with the following parameters Growth Percentage (\%), Plant Height (cm), Number of leaves (strands), and Number of tillers (stems). Data obtained were analyzed statistically, then continued with the Honestly Significant Difference Test (BNJ) at the level of 5\%. The results showed that the single treatment of the use of growing media did not have a significant effect on the parameters of observation of growth percentage (\%), plant height (cm), number of leaves (strands), and number of tillers (stems). The growth of growmore fertilizer also did not
\end{abstract}


show a significant effect on the parameters of observation of growth percentage (\%), plant height (cm), number of leaves (strands), and number of tillers (stems). Interaction of the use of various growth media and growmore fertilizer did not show a significant effect on the percentage of growth (\%), plant height (cm), number of leaves (strands), and number of tillers (stems).

Keywords: coir media coconut, growmore fertilizer, medium fern root, orchids, wood charcoal medium

Diterima: 3 Oktober 2018; disetujui 17 Oktober 2018

\section{PENDAHULUAN}

Anggrek merupakan salah satu kekayaan hayati, dimana keistimewaan tanaman anggrek tidak kalah dengan tanaman hias lainnya. Bahkan, jenis tanaman ini lebih dikenal orang dari pada tanaman hias lainnya. Untaian bunga yang tersusun beragam membuat orang tidak merasa bosan memelihara anggrek (Iswanto, 2010). Keunikan dan keindahan anggrek menjadi perbedaannya dengan tananaman lain. Dimana, anggrek memiliki bunga yang cantik dan beraneka ragam. Kecantikan bunga dihiasi dengan corak yang bervariasi hingga berpola.

Anggrek Dendrobium digemari karena tampilannya yang indah dan menggambarkan prestise bagi yang membudidayakannya dan yang menggunakannya, hingga banyak dinikmati oleh konsumen baik Nasional maupun Internasional. Permintaan yang terus meningkat harus diikuti dengan persediaan bibit dalam jumlah yang besar dan mutu yang baik. Proses budidaya anggrek memerlukan penanganan khusus terutama lingkungan tumbuhnya harus sesuai dengan habitat asli tanaman tersebut, agar pertumbuhan dan perkembangan tanaman menjadi lebih baik, terutama media tanam perlu mendapatkan perhatian khusus.

Media tanam anggrek sudah banyak diteliti dan digunakan untuk pertumbuhan bibit. Media tanam yang sering digunakan adalah arang, sabut kelapa, dan akar pakis. Media tanam tersebut tidak semuanya cocok untuk pertumbuhan dan perkembangan anggrek. Anggrek menghendaki media tanam yang dapat menyimpan air dan bebas dari jamur, bakteri dan mudah lapuk, karena anggrek merupakan tanaman yang bersifat epifit. Anggrek membutuhkan media tanam yang dapat menyediakan bahan organic sebagai sumber nutrisi yang dibutuhkannya. (Setiawan, 2003).

Media tanam sangat penting bagi pertumbuhan tanaman anggrek, dimana untuk mendapatkan hasil pertumbuhan yang maksimal haruslah menggunakan media yang sesuai dengan masing-masing anggrek, dari segi mendapatkan semua media ini sangat mudah dan harga relatif murah, dimana media-media ini dapat ditemukan dilingkungan hidup khususnya di Kabupaten Kuantan Singingi.

Anggrek Dendrobium yang diberi pupuk melalui daun lebih baik pertumbuhannya bila dibandingkan dengan penyerapan yang dilakukan hanya melalui akar. Pemupukan melalui daun lebih lebih efektif, seperti yang dilaporkan oleh Iswanto, (2010) bahwa penyerapan melalui daun dapat mencapai $90 \%$ dari seluruh hara yang diserap oleh tanaman anggrek untuk memenuhi kebutuhan hidupnya.

Pertumbuhan anggrek masuk dalam kategori sangat lambat. Sehingga untuk memacu pertumbuhan tersebut perlu dilakukan subtitusi pemupukan melalui dauan, dan pupuk daun yang diberikan 
adalah pupuk daun yang mengandung unsur hara makro dan mikro, salah satunya adalah pupuk daun Growmore.

Keunggulan growmore, dapat mempercepat pertumbuhan pada tanaman muda, mempercepat munculnya bunga pada tanaman hias serta dapat meningkatakan produksi buah. Pupuk growmore bisa digunakan pada semua jenis tanaman.

Dari hasil penelitian Kurniati (2004) pemberian Growmore dengan konsentrasi 2,0 g/ merupakan hasil yang terbaik bagi pertumbuhan tanaman anggrek Dendrobium.

Unsur hara $\mathrm{N}$ yang terkandung dalam Growmore diharapkan dapat meningkatkan pertumbuhan vegetative , sedangkan Posfor dapat menstimulir

\section{METODE PENELITIAN}

Penelitian dilakukan di Rumah Kaca (Green house) Fakultas Pertanian Universitas Islam Riau Jalan Kaharudin Nasution KM 13 Kelurahan Simpang Tiga, Kecamatan Bukit Raya, Kota Pekanbaru.

Bahan yang digunakan Bibit anggrek Dendrobium yang berasal dari hasil kultur jaringan, media tumbuh anggrek, seperti : pakis, arang kayu, dan sabut kelapa, pupuk Growmore (20-2020), Dithane 45, ember, air bersih.

Sedangkan alat yang digunakan adalah kayu, paku, martil, gergaji, ember, hand sprayer, pot tembikar ( tanah liat ), kawat, timbangan analitik, gelas ukur, dan alat tulis lainnya yang diperlukan.

Rancangan yang digunakan dalam penelitian ini adalah Rancangan Acak Lengkap (RAL) faktorial dengan 2 faktor,

\section{HASIL DAN PEMBAHASAN \\ Persentase tumbuh (\%)}

Pada tabel 1 dapat dilihat bahwa perlakuan secara tunggal penggunaan media tumbuh perlakuan terendah adalah $73.7 \%$ (M3). Dimana M3 merupakan pertumbhunan akar, dan mempercepat sense. Kalium berperan dalam proses metabolism yaitu sebagai katalisator (Ginting, 2001). Pemberian pupuk melalui daun harus memenuhi beberapa prinsip pemupukan antara lain, konsentrasi pupuk yang diberikan tidak boleh terlalu tinggi dan terlalu rendah. Tujuan Penelitian adalah Untuk mendapatkan media tumbuh pada aklimatisasi tanaman anggrek Dendrobium yang memberikan pertumbuhan paling baik. Untuk mengetahui uji pemberian pupuk Growmore pada aklimatisasi tanaman anggrek Dendrobium. Untuk mengetahui interaksi uji penggunaan media tumbuh dan pemberian pupuk Growmore pada aklimatisasi tanaman anggrek

Dendrobium.

faktor pertama adalah faktor (M) media tumbuh terdiri dari 3 taraf yaitu: $\mathrm{M} 1=$ Media Pakis; M2 = Media Arang kayu; M3 = Media Sabut kelapa; Faktor kedua adalah (G) pemberian pupuk Growmore dengan 4 taraf yaitu: G0 = tanpa pemberian pupuk Growmore; G1=pemberian pupuk Growmore 2 gr per liter; G2=pemberian pupuk Growmore 4 gr per liter; G3=pemberian pupuk Growmore 6 gr per liter; Dengan demikian terdapat 12 kombinasi perlakuan dan masing-masing terdiri dari 3 ulangan, setiap plot terdiri 4 tanaman dengan 3 tanaman sampel sehingga terdapat 36 plot. Maka populasi tanaman sebanyak 144 tanaman.

penggunaan madia tumbuh sabut kelapa, sabut kelapa memiliki keuntungan dapat menyerap air dengan baik dan adanya senyawa organik. Namun disebalik 
keuntungan tersebut media sabut kelapa juga memiliki kelemahan, salah satunya sabut kelapa bersifat mudah terurai dan menyerap banyak air sehingga jamur dan bakteri sangat mudah berkembang yang berakibat dapat mengganggu pertumbuhan dan perkembangan tanaman anggrek. Dendrobium dan hal ini juga diduga dapat berpengaruhnya terhadap persentase tumbuh pada tanaman anggrek.

Menurut Setiawan (2003), daya simpan air sangat tinggi pada media sabut kelapa, tetapi hal ini dapat menimbulkan serangan hama dan penyakit di bagian akar. Kelemahan pada media sabut kelapa mengakibatkan persentase tumbuh pada tanaman anggrek Dendrobium jumlah yang sangat terendah karena banyaknya ditemui anggrek tidak mampu hidup. Hal ini diketahui sebelumnya anggrek yang dipindahkan ke media perlakuan merupakan anggrek yang diaklimatisasi dari hasil kultur jaringan dan juga banyaknya terserang hama dan penyakit, karena kondisi anggrek yang sangat rentan terhadap faktor lingkungan.

Aklimatisasi merupakan masa adaptasi tanaman hasil pembiakan kultur jaringan (Yusnita, 2004), sejalan pendapat Herawan (2006) bahwa aklimatisasi adalah tahap kritis bagi tanaman anggrek Dendrobium karena sebelumnya kondisi lingkungan terkontrol sedangkan dilapangan kondisi lingkungan sulit dikontrol. Selain itu, persentase tumbuh juga dipengaruhi oleh komposisi daun dan akar yang seimbang saat diaklimatisasi. Menurut Trubus (2005), bahwa ciri-ciri planlet yang berkualitas itu tanaman bibit vigor, bebas dari hama dan penyakit, warna daun hijau, dan, serta komposisi daun dan akarnya seimbang. Setelah itu diikuikuti oleh perlakuan M1= penggunaan media akar pakis.

Perlakuan $\mathrm{M} 1=$ penggunaan media akar pakis menunjukan angka 74,5\% Akar pakis juga mempunyai keuntungan dimana mampu menyerap air dengan baik, struktur pakis yang miliki rongga udara mampu menjaga kelembaban media karena sirkulasi udaranya lancar. Widiastutoety, 2004; dan Don, Emir, dan Hadibroto, 2001 dalam Andalasari, Yafisham, dan Nuraini (2014) melaporkan bahwa media pakis memiliki keunggulan dibandingkan media tanam yang lain dalam menyimpan air, tata udara baik dan drainase yang baik, proses pelapukannya bertahap sehingga unsur hara yang dibutuhkan oleh anggrek dapat terpenuhi selama proses pertumbuhan. Media pakis mengandung senyawa gula, asam amino, asam alifatik, dan ester yang dibutuhkan tanaman anggrek, pakis juga tidak cepat lapuk sehingga tanaman mendapatkan unsur hara dalam waktu yang lama.

Perlakuan M2= penggunaan media arang kayu. Media arang kayu memiliki untungan dimana tidak mudah lapuk dan tidak mudah juga untuk ditumbuhi cendawan dan bakteri. Namun kelemahan dari arang kayu tidak dapat mengikat air terlalu lama, sesuai dengan sifat arang yang gampang menyerap air dan gampang pula untuk melepaskan atau menguapkan air yang diterimah nya. Maka penyiram diharuskan dapat lebih terkontrol agar kebutuhan akan air tanaman tetap terpenuhi. Dimana, dari penyiraman yang dilakukan arang hanya bisa mampu menahan air dalam jumlah sedikit. Surtinah, dan Mutryarny, 2013) melaporkan bahwa media tumbuh yang memenuhi syarat untuk pertumbuhan anggrek adalah media tanam yang dapat mempertahankan kelembaban dan dapat sebagai tempat menyimpan hara yang dibutuhkan oleh tanaman anggrek.

Persentase tumbuh pada perlakuan media arang (M2) menunjukkan angka 75 $\%$ merupakan angka yang tertinggi. Hal ini diduga karena arang yang memiliki keuntungan yang tidak mudah lapuk dan tidak mudah untuk ditumbuhi cendawan dan bakteri, sehingga tanaman anggrek dapat bertahan hidup dan tidak banyaknya 
ditemui anggrek yang mati. Selain itu, media arang juga dapat menetralisir kelebihan pupuk bagi tanaman, serta arang yang memiliki carbon aktif yang dapat bekerja dan mempengaruhi pertumbuhan tanaman khususnya anggrek Dendrobium. Sesuai pendapat Agah (2009), bahwa sifat arang yang tidak dapat mengikat air terlalu banyak maka penyiraman perlu diseringkan, dan arang juga tidak dapat ditumbuhi cendawan dan bakteri. Penggunaan Growmore dapat memenuhi kebutuhan hara bagi tanaman anggrek, diman growmore merupakan salah satu pupuk daun yang mengandung unsur hara makro dan mikro, berbentuk kristal dan larut dalam air. Growmore mengandung unsur hara yang terdiri dari $\mathrm{N}, \mathrm{P}, \mathrm{K}, \mathrm{Mg}$, $\mathrm{S}, \mathrm{Ca}, \mathrm{Fe}, \mathrm{Zn}, \mathrm{Cu}$, dan Mo (Anonim, 2011).

Setiap tanaman memerlukan unsur hara untuk pertumbuhan, maka dengan perlakuan Growmore dapatnya terpenuhi kebutuhan hara tanaman anggrek khususnya unsur hara makro yang dalam jumlah lebih banyak. Febrizawati, Murniati, dan Yoseva, 2014, melaporkan bahwa pemberian Growmore $1.5 \mathrm{~g}$ per liter air dengan media campuran pakis, arang, dan sabut kelapa menunjukkan hasil terbaik pada pertumbuhan bibit anggrek Dendrobium. Unsur hara yang terkandung dalam Growmore seperti N, berperan dalam reaksi enzim, $P$ berperan pada fosporilasi, dan $\mathrm{K}$ berperan dalam mengatur proses bukaan stomata (Febrizawati, Murniati, dan Yoseva, 2014

Perlakuan Growmore menunjukan angka yang tertinggi yaitu $76 \%$ adalah pemberian growmore 6 gr per liter (G3), hal ini diduga bahwa dengan perlakuan 6 gr perliter telah dapat mencukupi hara tanaman anggrek Dendrobium. Lidar dan Surtinah (2012), menjelaskan bahwa pemberian pupuk dengan range yang terlalu kecil dapat berdampak terhadap hasil yang berbeda tidak nyata, sedangkan pad range yang terlalu besar menyebabkan seluruh perlakuan akan berbeda nyata.

\section{Tinggi Tanaman $(\mathrm{cm})$}

Pada tabel 2 menunjukkan bahwa tinggi tanaman tertinggi adalah perlakuan $\mathrm{M} 2=5.78 \mathrm{~cm}$, diikuti oleh M3 $=5.43 \mathrm{~cm}$, dan $\mathrm{M} 1=5.37 \mathrm{~cm}$ penggunaan berbagai media tumbuh dan pupuk Growmore tidak menunjukkan interaksi terhadap pertumbuhan tinggi tanaman. Anggrek Dendrobium. Perlakuan M2 = media arang kayu yang menunjukkan angka yang tertinggi, hal ini diduga karena keuntungan dari sifat media arang kayu itu dapat menjadi penawar bila kelebihan pupuk pada tanaman, dan pengotrolan penyiraman. Sesuai dengan pendapat Agah (2009) bahwa sifat arang yang tidak terlalu banyak mengikat air maka dipelukan penyiram yang sering.

Anggrek yang dipindahkan ke media perlakuan, adalah anggrek yang masih dalam kondisi kultur jaringan juga menggunakan arang. Namun, bedanya arang yng digunakan dimedia kultur jaringan dalam keadaan halus. Kondisi ini tidak terlalu mempengaruhi terhadap fisiologi tanaman, maka sesuai dengan persentase tumbuh anggrek dapat bertahan hidup dan begitu juga terhadap tinggi tanaman.

Tingginya persentase tumbuh, maka tinggi tanaman pun bertambah. Namun perlu perawat atau pemeliharaan yang dilakukan pada saat perlakuan seperti penyiraman agar air dapat tersedia. Pendapat Aritonang dan Surtinah (2018) menjelaskan bahwa air dan ketersediaan unsur hara pada tanaman akan membantu proses pembelahan sel dan pembesaran sel, dengan unsur hara yang cukup maka organel sel yang berperan dalam menghasilkan makanan bagi tanaman akan terbentuk maksimal dan dapat berfungsi secara maksimal.

Media arang terserang tidak mudah terserang cendawan dan bakteri sehingga 
akar dapat berkembang dan menyerap hara serta pertambahan tinggi tanamapun berlangsung.

Perlakuan $\mathrm{M} 1=$ media pakis merupakan tanaman yang terendah yaitu $5.37 \mathrm{~cm}$, hal ini diduga karena tidak dapatnya akar tanaman untuk berkembang. Dimana media pakis memiliki kelemahan apabila terlalu sering disiram media akan terlalu basah dan mengundang cedawan, Agah (2009) menyatakan bahwa media akar pakis dapat menyerap air dengan baik, namun mudah lapuk dan dapat mengundang cendawan. Selanjutnya Selanjutnya Surtinah (2007) mengatakan bahwa kelebihan air akan respirasi akar menjadi anaerob, sehingga hasil dari respirasi yang berupa energy tidak mencukupi kebutuhan tanaman.

Tinggi tanaman tidak hanya ditentukan oleh berbagai media tumbuh namun pemberian pupuk Growmore yang mengandung unsur $\mathrm{N}$ berperan dalam memacu pertumbuhan tinggi bibit. Surtinah (2007) melaporkan bahwa seluruh pupuk daun yang diuji coba mengandung unsur hara Nitrogen yang cukup tinggi, tidak memberikan perbedaan pertumbuhan vegetative tanaman jagung manis. Mardawilis (2004) menyebutkan bahwa tanaman untuk tumbuh optimal membutuhkan N, P, dan K yang optimal.

Perlakuan Growmore yang menunjukan angka tertinggi yaitu $5.84 \mathrm{~cm}$ perlakuan $\mathrm{G} 1=$ pemberian Growmore $2 \mathrm{gr}$ per liter. Hal ini diduga dengan pemberian growmore $2 \mathrm{gr} /$ liter dapat mempengaruhi pertumbuhan bibit anggrek, hal ini diduga karena fungsi dari $\mathrm{N}$, seperti yang dijelaskan oleh Jumin (2002) bahwa N dapat merangsang pertunasan dan penambahan tinggi tanaman. Pemberiaan Nitrogen $(\mathrm{N})$ dapat memacu pembentukan klorofil lebih banyak sehingga fotosintesis akan berlangsung lebih optimal (Surtinah, 2018).

Perlakuan growmore terendah ditunjukan oleh angka $5.27 \mathrm{~cm}$ yaitu pada perlakuan $\mathrm{G} 2=$ pemberian Growmore $4 \mathrm{gr}$ per liter. Hal ini diguda karena pemberian 4 gr per liter pada tanaman akan mengakibatkan keracunan pada tanaman anggrek Dendrobium. Pemberian pupuk pada tanaan harus memperhatikan prinsipprinsip pemupukan, salah satunya adalah tepat dosis, bila terlalu sedikit diberikan tanaman akan kekurangan unsur hara begitu juga sebaliknya. Nurmayanti (2008), menjelaskan bahwa tanaman yang kekurangan unsur hara makro akan memperlihatkan pertumbuhan yang tidak optimal.

\section{Jumlah Daun ( helai )}

Berdasarkan pengamatan persentase tumbuh (\%) dan pengamatan tinggi tanaman $(\mathrm{cm})$ perlakuan $\mathrm{M} 2=$ media arang kayu menunjukkan angka yang terbaik, begitu juga dengan jumlah daun tanaman anggrek Dendrobium. Dapat dilihat pada tabel diatas perlakuan media tanaman $\mathrm{M} 2=$ arang kayu memiliki jumlah daun yang paling banyak yaitu 3 . 47 helai, diikuti M3 = media tanaman sabut kelapa yitu 3.44 helai dan M1 = akar pakis yaitu 3.36 helai, hal ini disebabkan karena penggunaan $\mathrm{M} 2=$ media arang kayu dapat menetralisis kelebihan pupuk dan unsur hara serta dapat mengurangi tingginya kelembaban yang diakibatkan penyiraman yang berlebihan dan struktur sifik daun serta aktivitas fisiologis anggrek. Semakin baiknya persentase tumbuh (\%) maka pertumbuhan tinggi tanaman $(\mathrm{cm})$ juga akan ikut membaik, begitu juga dengan jumlah daun (helai) dari tanaman itu. Besarnya jumlah daun pada $\mathrm{M} 2=$ media arang kayu ini diduga juga karena media yang digunakan memberikan pertumbuhan yang baik bagi tanaman, menurut Agah (2009), keunggulan media arang selain dapat menawar kelebihan pemberian pupuk dan media arang juga tidak mudah lapuk sehingga penggunaan media arang lebih 
lama serta arang mudah didapat dengan harga yang murah.

Perlakuan $\mathrm{M} 1=$ Media pakis menunjukan angka yang terendah yaitu 3.36 helai. Hal ini diduga karena dari daya serapnya yang tinggi terjadi kelebihan air pada tanaman namun dapat menghambat pertumbuhan tanaman, karena ditemukan tanaman membusuk. Agah (2009) menyatakan bahwa media akar pakis dapat menyerap air dengan baik, namun mudah lapuk dan dapat mengundang cendawan.

Banyaknya jumlah daun juga dapat dipengaruhi pemberian pupuk Growmore yang diduga kandungan N pada Growmore sudah mencukupi kebutuhan bibit anggrek Dendrobium.terutama dalam pembentukan klorofil pada organ daun.

Aritonang dan Surtinah (2018) melaporkan bahwa kandungan klorofil yang maksimal pada daun akan mempengaruhi pertumbuhan tanaman, dengan intensitas cahaya yang cukup maka peranan klorofil dalam menyerap cahaya yang akan meningkatkan proses fotolisis yang akan menghasilkan bahan yang akan digunakan untuk melaksanakan reaksi gelap untuk menghasilkan karbohidrat sebagai sumber makanan tanaman sel.

Perlakuan tertinggi ditunjukan oleh G3 $=$ pemberian Growmore 6 gr per liter yaitu 3.59 helai. Hal ini diduga bahwa dengan perlakuan $6 \mathrm{gr} /$ liter telah dapat mencukupi hara tanaman anggrek Dendrobium, sesuai yang ditemukan pada persentase tumbuh. Jumlah daun baru dapat diketahui bila tanaman sudah tumbuh dengan baik. Lidar dan Surtinah (2012) melaporkan pada konsentrasi yang rendah perlakuan yang diberikan tidak memperlihatkan pengaruh nyata, sedangkan pada konsentrasi yang besar seluruh perlakuan dapat mengakibatkan berpengaruh nyata.

\section{Jumlah Anakan (batang)}

Berdasarkan pengamatan persentase tumbuh (\%), tinggi tanaman $(\mathrm{cm})$, dan jumlah daun (helai) dapat terlihat bahwa pertumbuhan anggrek boleh dikatakan sempurna, maka akan sempurna juga pada pertamabahan anakan. Pada pertumbuhan tanaman itu, Jika fase vegetatifnya tidak terganggu maka barulah tanaman itu bergenerasi ke fase geratif yaitu pertambahan anakan.

Tabel diatas menunjukan penggunaan media yang terbaik terlihat pada perlakuan M1= media akar pakis yaitu 1.25 batang. Hal ini diduga media pakis yang dipakai dapat memehuni unsur hara yang dibutuhkan tanaman, dimana media pakis memiliki keunggulan-keungulan sehingga digunakan untuk mebudidayakan anggrek. Campuran media tanam pakis, arang kayu dan sabut kelapa ditambah $1.5 \mathrm{~g}$ per liter air Growmore menghasilkan pertumbuhan bibit yang terbaik (Febrizawati, Murniati, dan Yoseva, 2014)

Sifat akar pakis yang menguntungkan yaitu memiliki cukup kadar hara, maka perkembang akar tanaman angrek juga dapat berkembanga dengan leluasa dimana media pakis juga memiliki rongga udara. Anakan angrek akan dapat muncul pada media yang dapat menyediakan hara, tetapi pertumbuhan anakan ini baru bisa terjadi pada rizoma yang tumbuh menjalar yang berasal dari kuncup tidur pada ruas rhizoma atau pangkal batang yang bertunas dan membentuk batang baru, Martin (2008) menambahkan bahwa munculnya anakan ini pada rhizoma yang tumbuh menjalar yang berasal dari kuncup tidur pada ruas rhizom atau dari pangkal batang yang bertunas dan batang baru dipengaruhi oleh pembesarannya sel-sel nonmeristematik dengan begitu pertumbuhan anakan anggrek sangat terbatas.

Bedasarkan ciri pertumbuhan anggrek Dendrobium, yang sympodial pertumbuhan anakan anggrek juga sangat terbatas, tapi dapat juga dipacu dengan pemberian pupuk Growmore. Dimana pupuk growmore diberikan dengan melalui penyemprotan melalui daun. Pendapat 
Iswanto (2002), bahwa tanaman anggrek mampu menyerap pupuk $90 \%$ dari daun dan $10 \%$ dari akar.

Perlakuan

\section{Growmore}

yang menunjukan angka tertinggi adalah perlakuan G3= pemberian Growmore $6 \mathrm{gr}$ per liter. Sama yang terjadi pada pengamatan persentase tumbuh (\%) dan pengamatan jumlah daun (helai) dimana perlakuan Growmore itu telah memberikan unsur hara yang cukup bagi pertumbuhan tanaman anggrek. Selain media tumbuh dan pemberian pupuk Growmore pertumbuhan anakan anggrek juga dipengaruhi oleh faktor lingkungan dan faktor genetik, Surtinah dan Mutryarny (2013) bahwa pertumbuhan dan perkembangan tanaman yang tidak respon terhadap perlakuan sering terjadi, dan diduga bahwa factor genetic lebih dominan mempengaruhi pertumbuhan tanaman dibandingkan factor lingkungannya.

Tabel 1. Rerata pada pengamatan persentase tumbuh tanaman anggrek Dendrobium dengan menggunakan berbagai media tumbuh dan pemberian pupuk growmore $(\%)$

\begin{tabular}{lccccc}
\hline \multirow{2}{*}{ Media } & \multicolumn{4}{c}{ Perlakuan Growmore } & \multirow{2}{*}{ Rerata } \\
\cline { 2 - 5 } & $0 \mathrm{~g} \mathrm{l}^{-1}$ & $2 \mathrm{~g} \mathrm{l}^{-1}$ & $4 \mathrm{~g} \mathrm{l}^{-1}$ & $6 \mathrm{~g} \mathrm{l}^{-1}$ & 74.5 \\
Pakis & 75 & 76 & 70 & 77 & 75 \\
Arang kayu & 77 & 74 & 74 & 75 & 73.7 \\
M3sabut kelapa & 73 & 73 & 75 & 74 & \\
\hline Rerata & 74 & 74 & 72 & & \\
\hline KK=0.23 & & & &
\end{tabular}

Tabel 2. Rerata pada pengamatan tinggi tanaman anggrek Dendrobium dengan menggunakan berbagai media tumbuh dan pemberian pupuk growmore

\begin{tabular}{lccccc}
\hline \multirow{2}{*}{ Media } & \multicolumn{4}{c}{ Perlakuan Growmore } & \multirow{2}{*}{ Rerata } \\
\cline { 2 - 5 } & $0 \mathrm{~g} \mathrm{l}^{-1}$ & $2 \mathrm{~g} \mathrm{l}^{-1}$ & $4 \mathrm{~g} \mathrm{l}^{-1}$ & $6 \mathrm{~g} \mathrm{l}^{-1}$ & 5.37 \\
\hline Pakis & 5.26 & 5.23 & 5.58 & 5.42 & 5.78 \\
Arang kayu & 5.42 & 6.13 & 5.44 & 6.13 & 5.43 \\
Sabut kelapa & 5.58 & 6.17 & 4.79 & 5.17 & \\
\hline \multicolumn{1}{c}{ Rerata } & 5.42 & 5.84 & 5.27 & 5.57 & \\
\hline KK=9.9\% & & & & &
\end{tabular}

Tabel 3. Rerata pada pengamatan jumlah daun tanaman anggrek Dendrobium dengan menggunakan berbagai media tumbuh dan pemberian pupuk growmore

\begin{tabular}{|c|c|c|c|c|c|}
\hline \multirow[t]{2}{*}{ Media } & \multicolumn{4}{|c|}{ Perlakuan Growmore } & \multirow[t]{2}{*}{ Rerata } \\
\hline & $0 \mathrm{~g} \mathrm{l}^{-1}$ & $2 \mathrm{~g} \mathrm{l}^{-1}$ & $4 \mathrm{~g} \mathrm{l}^{-1}$ & $6 \mathrm{~g} \mathrm{l}^{-1}$ & \\
\hline Pakis & 3.22 & 3.56 & 3.00 & 3.67 & 3.36 \\
\hline Arang kayu & 3.67 & 3.44 & 3.56 & 3.22 & 3.47 \\
\hline Sabut kelapa & 3.11 & 3.44 & 3.33 & 3.89 & 3.44 \\
\hline Rerata & 3.33 & 3.48 & 3.30 & 3.59 & \\
\hline $\mathrm{KK}=13.67 \%$ & & & & & \\
\hline
\end{tabular}


Tabel 4. Rerata pada pengamatan jumlah anakan tanaman anggrek Dendrobium dengan menggunakan berbagai media tumbuh dan pemberian pupuk growmore

\begin{tabular}{|c|c|c|c|c|c|}
\hline \multirow{2}{*}{ Media } & \multicolumn{4}{|c|}{ Perlakuan Growmore } & \multirow[t]{2}{*}{ Rerata } \\
\hline & $0 \mathrm{~g} \mathrm{l}^{-1}$ & $2 \mathrm{~g} \mathrm{l}^{-1}$ & $4 \mathrm{~g} \mathrm{l}^{-1}$ & $6 \mathrm{~g} \mathrm{l}^{-1}$ & \\
\hline Pakis & 0.89 & 1.22 & 1.56 & 1.33 & 1.25 \\
\hline Arang kayu & 1.33 & 0.89 & 1.22 & 1.44 & 1.22 \\
\hline Sabut kelapa & 0.78 & 1.44 & 1.33 & 1.33 & 1.22 \\
\hline Rerata & 1.00 & 1.19 & 1.37 & 1.37 & \\
\hline $\mathrm{KK}=0.47 \%$ & & & & & \\
\hline
\end{tabular}

\section{SIMPULAN}

Hasil yang diperoleh berdasarkan analisis data bahwa perlakuan kombinasi Growmore dan Media tanam yang dieplikasikan pada bibit anggrek belum dapat mamacu pertumbuhan dan perkembangan bibit anggrek Dendrobium.
Demikian juga pada pengaruh utama media tanam dan Growmore terhadap seluruh parameter pengamatan tidak memperlihatkan kemampuannya dalam mempengaruhi pertumbuhan bibit anggrek Dendrobium.

\section{UCAPAN TERIMA KASIH}

Terimah kasih kepada semua pihak yang telah membantu terlaksananya penelitian ini terutama kepada dosen pembimbing yang telah menyediakan waktunya untuk memberikan bimbingan,

\section{DAFTAR PUSTAKA}

Andalasari, T.D., Yafisham, dan Nuraini, 2014. Respon Pertumbuhan Anggrek Dendrobium terhadap Jenis Media Tanam dan Pupuk Daun. Jurnal Penelitian Pertanian Terapan, Vol. 14 (3): 167-173.

Anonim. 2011. Pemupukan Anggrek. Nusa Tani. Jakarta.

Agah. 2009. Aklimatisasi Tanaman Hias. Penebar Swadaya. Jakarta.

Aritonang, S., \& Surtinah, S. (2018). Stimulasi Hasil Melon (Cucumis melo, L) Dengan Menggunakan Bioto Grow Gold (BGG). Jurnal Ilmiah Pertanian, 15(1), 35-41.

Febrizawati, Murniati, dan Yoseva, S., 2014. Pengaruh Komposisi Media Tanam Dengan Konsentrasi Pupuk Cair terhadap Pertumbuhan dan terimakasih diucapkan kepada keluarga besar yang telah mendukung selesainya penelitian ini baik moril mauteril.

Tanaman Anggrek Dendrobium (Dendrobium, sp.). JOM Faperta, Vol. 1 (2): 1-12.

Ginting, B. 2001. Pengaruh Cara Pemberian Air, media, dan Pemupukan Anggrek Dendrobium. Balai Penelitian Tanaman Hias. Jakarta.

Herawan, 2006. mengenal Anggrek. Penerbit Penebar Swadaya. Jakarta.

Iswanto, H, 2010. Petunjuk Praktis Merawat Anggrek. Agro Media. Jakarta.

Jumin, H. B., 2002. Dasar-dasar Agronomi. Raja Grafindo. 264 hal. Kurniati, R. 2004. Induksi Keragaman Genetik Phalaenopsis Hinamatsuri x Doritaenopsis Modern Beauty dan Phalaenopsis Ambilis "Formosa" $x$ 
Phalaenopsis Taipei Gold "GS" dengan Menggunakan Iradiasi Sinar Gamma. Tesis, Program Pasca Sarjana. Institut Pertanian Bogor. Bogor. 54hal.

Lidar, S. Surtinah.(2012). Respon Tanaman Jagung Manis (Zea mays saccharata, Sturt) Akibat Pemberian Tiens Golden Harvest. Jurnal Ilmiah Pertanian, 8(2), 1-5.

Martin, G.A. 2008. Fisiologi tanaman. Cambridge University Press. Cambridge.

Nurmayanti, T.R, 2008. Efektifitas air kelapa dan ampas the terhadap pertumbuhan Tanaman Sri Rejeki pada Media Tanaman yang berbeda. Skripsi Fakultas Keguruan dan Ilmu Pendidikan. Universitas Muhammadiyah. Surakarta

Mardawilis. 2004. Pupuk Akar Jenis dan Aplikasi. Penebar Swadaya. Jakarta.

Trubus. 2005. Memelihara Anggrek.

Penebar swadaya. Jakarta
Setiawan, L. 2003. Merawat Dendrobium. PT Penebar Swadaya. Jakatar.

Surtinah, S. (2007). Menguji 5 Macam Pupuk Daun Dengan Mengukur Kadar Gula Total Biji Jagung Manis (Zea mays saccharata). Jurnal Ilmiah Pertanian, 3(2), 1-6.

Surtinah, S., dan Mutryarny, E. (2013). Frekuensi Pemberian Grow Quick LB Terhadap Pertumbuhan Bibit Anggrek Dendrobium Pada Stadia Komunitas Pot. Jurnal Ilmiah Pertanian, 10(2), 31-40.

Surtinah, S., 2018. AGRONOMIC PERFORMANCE OF SWEET CORN (Zea mays saccharata, Sturt) IN RUMBAIDISTRICT PEKANBARU. AGROLAND: The Agricultural Sciences Journal, 5(1), 53-58.

Yusnita. 2004. Cara aklimatisasi anggrek. 